\title{
Ortaöğretim Öğrencilerinin Oyun Kavramına ve Fiziksel Aktivite İçeren Oyunları Oynamaya Yönelik Tutumlarının Bazı Değişkenler Açısından İncelenmesi*
}

\author{
Erdal YELTEKİN ${ }^{1}$ (D) \& Fikret ALINCAK ${ }^{2 * *}$ (D)
}

\author{
Gönderilme Tarihi:09 Haziran $2021 \quad$ Kabul Tarihi: 20 Haziran 2021 \\ DOI: $10.52974 /$ jena. 950283
}

\begin{abstract}
$\ddot{O} z:$
Son yıllarda gelişmiş ülkelerin ĕgitim sistemlerine baktı̆̆ımızda oyun kavramının çocukların gelişimi açısından önemli bir faaliyet olduğu görülmektedir. Bilim adamlarının birçoğuna göre çocuğu tanımak ve gözlemlemenin en iyi yolu oyundur. Çocuklar oyun oynadiğı esnada birçok beceri kazanırlar. Genellikle oyun esnasında öğrenme, etkili karar verme, birlikte iş yapma, dürüstlük, paylaşmak, karşısındakilerin haklarına saygı göstermek, arkadaşlarını sevme, yardımlaşma gibi durumları öğrenir. Çocuk, oyun vasitasıyla yetişkinliğe geçiş dönemindeki becerilerini izleyerek pratik hale getirir ve mükemmelleştirir. Oyun, her yaş evresinde insanların gelişiminde faydal ve etkili bir kavramdır. Bu araştırma, ortaöğretim öğrencilerinin oyun kavramına ve fiziksel aktivite içeren oyunları oynamaya yönelik tutumlarının bazı değişkenler açısından incelenmesi amacıyla yapılan betimsel bir çalışmadır. Bu araştırmada nicel ve nitel verilerin bir arada analiz edildiği karma yöntem kullanılmıştır. Araştırma evrenini Gaziantep İl Milli Eğitim Müdürlüğ̈̈’ne bağlı okullarda öğrenim görmekte olan ortaöğretim öğrencileri, örneklem grubunu ise gönüllülük esasına dayalı olarak seçilen 613 (227 kadın, 386 erkek) öğrenci oluşturmaktadır. Araştırmada veri toplama aracı olarak, Hazar (2015) tarafindan geliştirilen "Oyunsallık Ölçeği”" kullanılmıştır. Verilerin analizinde SPSS 20.0 paket programindan yararlanilarak, Independent Sample $t$ testi, OneWay Anova testi kullanılmıştır. Ayrıca, araştırma grubuna yarı yapılandırılmış görüşme formu uygulanarak, elde edilen nitel veriler, içerik analizi yöntemiyle çözümlenmiştir. Araştırma sonucunda, erkeklerin kadınlardan daha yüksek oyunsallık ĕgilimleri olduğu, yaş ve sınıf değişkenleri açısından küçük yaş ve sınıf gruplarının oyunsallık puanlarının daha yüksek olduğu, spor geçmişi olan öğrencilerin fiziksel aktivite içeren oyunlara yönelik tutumlarının daha olumlu olduğu, Anadolu ve Fen Lisesi ögrencilerinin sosyal uyum alt boyutu puanlarının daha yüksek olduğu sonucuna ulaşılmıştır. Ayrıca, kilonun arttı̆̆ durumlarda oyun tutkusu, oyun isteği ve keyif alma düzeylerinin azaldiğl belirlenirken, boy ile ilgili herhangi bir ilişki bulunamamıştır. Çalışmaya katılan ögrencilerin oyun kavramına ilişkin görüşlerinde kendini tanımak, ögrenmenin ilk adımı, keyif ve mutluluk, eğlenmek temalarının ön plana çıktığı, oyunun faydalarına ilişkin görüşleri incelendiğinde çoğunluğu oyunun faydalı olduğunu, ancak okul ortamında oyun alanlarının yeterli olmadiğ yönünde sonuçlara ulasilmistır.
\end{abstract}

Anahtar Kelimeler: Öğrenci, fiziksel aktivite, oyun.

\footnotetext{
${ }^{1}$ Milli Eğitim Bakanlığı, Türkiye, Orcid ID: 0000-0002-1947-982X

${ }^{2}$ Gaziantep Üniversitesi, Türkiye, Orcid ID: 0000-0003-3459-3441

*Bu Çalışma birinci yazarın Gaziantep Üniversitesi Sağlık Bilimler Enstitüsü tarafından kabul edilen yüksek lisans tezinden üretilmiştir.

*** Sorumlu Yazar (Corresponding Author): alincakfikret27@gmail.com
} 


\begin{abstract}
:
When we look at the education systems of developed countries in recent years, it is seen that the concept of play is an important activity for the development of children. According to many scientists, the best way to get to know and observe the child is through play. Children gain many skills while playing. Generally, they learn situations such as learning during the game, making effective decisions, working together, honesty, sharing, respecting the rights of others, loving their friends, helping each other. Through play, the child monitors and perfects his/her skills in transition to adulthood. Play is a useful and effective concept in the development of people at every age stage. This research is a descriptive study to examine the attitudes of secondary school students towards the concept of game and playing games containing physical activity in terms of some variables. In this study, a mixed method, in which quantitative and qualitative data were analyzed together, was used. The research population consists of secondary school students studying in schools affiliated to Gaziantep Provincial Directorate of National Education, and the sample group consists of 613 students (227 Female, 386 Male) selected on a voluntary basis. The "Playfulness Scale" developed by Hazar (2015) was used as a data collection tool in the research. Independent Sample t test and OneWay Anova test were used in the analysis of the data by using the SPSS 20.0 package program. In addition, the qualitative data obtained by applying a semi-structured interview form to the research group were analyzed by content analysis method. As a result of the research, it was found that men have higher playfulness tendencies than women, younger age and class groups have higher playfulness scores in terms of age and class variables, students with a sports background have more positive attitudes towards games involving physical activity, Anatolian and Science high school students' social cohesion sub-dimension It was concluded that the scores were higher. In addition, when the weight increased, it was determined that the passion for the game, the desire to play and the level of enjoyment decreased, but no relationship was found with the height. In the opinions of the students participating in the study on the concept of game, the themes of knowing oneself, the first step of learning, pleasure and happiness, and having fun came to the fore, and when the views on the benefits of the game were examined, it was concluded that the majority of the game was beneficial, but the playgrounds were not sufficient in the school environment.
\end{abstract}

Keywords: Secondary education, student, physical activity, game.

\title{
Gİiș
}

Oyun yüzyıllardır süregelen ve insan hayatının önemli bir parçası olan olgudur. İnsan hareketlerinin doğal bir parçası olarak ortaya çıktığı düşünülen oyun günümüzde ise çeşitli şekiller ve platformlarda yerini almaktadır. Çeşitli değişimler ile de geleneksel oyunların yerini günümüzde dijital platformlarda oynanan oyunların aldığı görülmektedir. Çocuğun eğitim hayatının gelişiminde oyun oldukça etkilidir. Çocuğun fiziksel, duygusal, sosyal ve zihinsel özellikleri oyun yoluyla gelişmektedir. Dolayısıyla aileler tarafından küçük yaşlarda oyunlara sevk edilen çocuklarda bir takım psikomotor beceri özellikleri gelişmektedir.

Genel manada oyun etkinlikleri her yaş döneminde etkili olmakla birlikte çocukların gelişim döneminde daha da önemlidir. Bu anlamıyla oyun, çocuklar için bir zorunlu ihtiyaçtır. Dolayısıyla çocuk oyun esnasında gerek içerisinde bulunduğu kültürel çevreden gerekse de genetik anlamda reaksiyon göstermektedir. Bundan dolayı bilim adamlarının birçoğu çocuğu tanımak için oyunun en öneli araç olduğunu belirtmektedirler. Özellikle okul döneminde çocuklar kişisel özelliklerine yönelik olarak merak uyandırıcı ve yaratıcı oyunlara karşı olumlu tutum göstermektedir (Hazar, 2000).

Oyun çocukların eğitiminin ilk dönemlerinden itibaren önemli bir ihtiyacı olmuştur. Çocukların sağlıklı gelişimleri için bu ihtiyaçlarının kısıtlanmaması gerekliliği ortaya çıkmaktadır. Çünkü çocukların hayata hazırlanması için gerekli olan birçok deneyimi oyunlar aracılığıyla gerçekleştirmektedir (Ayan, 2007). Birçok bilim insanına göre oyun çocuğu tanımada en etkili yol olduğu vurgulanmaktadır. Oyun ayrıca çocuk için iyi bir eğitim aracı olduğunu yadsınamaz bir gerçektir (Ayan \& Dündar, 2009). Eğitim sürecinin her evresi 
çocukları topluma kazandırma ve geleceğe hazırlama konusunda oldukça önemlidir. Tüm toplumlarda bu ortak görev, çocukların zihinsel, duygusal, sosyal ve psikolojik ihtiyaçlarının yanı sıra beslenme, barınak ve sağlı gibi fiziksel ihtiyaçlarının karşılanması olarak değerlendirilir (Ekinci \& diğ., 2019).

Tekkurşun Demir ve Cicioğlu (2018)'na göre insanların sağlıklı bir yaşam elde etmelerinde oldukça etkili olan fiziksel aktivitenin bir takım nedenlerden dolayı gün geçtikçe azaldığı belirtilmektedir. İnsanlarda meydana gelen aşırı şekilde iş yoğunluğu beraberinde yorgunluğu arttırırken insanların fiziksel aktiviteler katılımını da uzaklaştırmaktadır. Özellikle teknolojinin her alanda ilerlemesi ve gelişmesi sonucunda insanların fiziksel aktivite içeren oyunları terk ettikleri görülmektedir.

Ayrıca düzenli olarak yapılan fiziksel aktivite sonucunda insanların motivasyon düzeyinin arttığı ve daha mutlu bir yaşam elde ettikleri ifade edilmektedir (İlhan, 2010).

Barnett ve Storm, (1981) birçok açıdan oyunun insanların gelişimi açısından yararı olduğunu belirtmektedirler. Oyun bireye farkında olarak veya olmayarak stres ve kriz anını yönetme, kontrol edebilme yeteneği vermektedir. Oyun, oynayanların motivasyonunu maksimum seviyeye çıkarır (Nikfarjam, 2012).

Oyunların güçlü bir organizma, sağlıklı bir vücut yapısı, çeşitli motor becerilerin gelişimi açısından etkili olduğu görülmektedir. Oyunsallık öncelikle çocuklarda, aslında her yaş döneminde oyun oynamaya yatkınlık (isteklilik) olarak kabul edilir. Buradan hareketle fiziksel oyun oynama isteği oldukça önemlidir. Bu kapsamda çalışmadan alınan ortaöğretim öğrencilerinin oyun kavramı ve fiziksel aktivite içeren oyunları oynamaya yönelik tutumları incelenerek bilimsel verilerin ortaya konulması ve yapılacak diğer araştırmalara yarar sunması açısından önem arz edeceği düşünülmektedir.

- Ortaöğretim öğrencilerinin cinsiyet değişkeni açısından fiziksel aktivite içeren oyunları oynamaya yönelik tutumları farklılık göstermekte midir?

- Ortaöğretim öğrencilerinin yaş grupları değişkeni açısından fiziksel aktivite içeren oyunları oynamaya yönelik tutumları farklılık göstermekte midir?

- Ortaöğretim öğrencilerinin sınıf değişkeni açısından fiziksel aktivite içeren oyunları oynamaya yönelik tutumları farklılık göstermekte midir?

- Ortaöğretim öğrencilerinin spor geçmişi durumu değişkeni açısından fiziksel aktivite içeren oyunları oynamaya yönelik tutumları farklılık göstermekte midir?

- Ortaöğretim öğrencilerinin öğrenim gördüğ̈ okul türü değişkeni açısından fiziksel aktivite içeren oyunları oynamaya yönelik tutumları farklılık göstermekte midir?

- Ortaöğretim öğrencilerinin kilo ve boy değerleri değişkeni açısından fiziksel aktivite içeren oyunları oynamaya yönelik tutumları farklılık göstermekte midir?

- Ortaöğretim öğrencilerinin oyun kavramına ilişkin görüşleri nelerdir?

- Ortaöğretim öğrencilerinin oyunun faydalarına ilişkin görüşleri nelerdir?

- Ortaöğretim öğrencilerinin öğrenim gördükleri okulda bulunan oyun alanlarının yeterliliğine ilişkin görüşleri nelerdir?

\section{YÖNTEM}

Bu çalışmada, ortaöğretim öğrencilerinin oyun kavramına ve fiziksel aktivite içeren oyunları oynamaya yönelik tutumlarının bazı değişkenler açısından incelenmesi amacıyla karma 
yöntem desenlerinden açıklayıcı ardışık desen kullanılmıştır. Cresswell ve Plano Clark (2007) karma yöntemi, hem nicel hem de nitel verilerin toplanarak analiz edildiği ve elde edilen verilerin bütünleştirildiği bir araştırma yaklaşımı olarak tanımlamışlardır (Yıldırım \& Şimşek, 2013). Açıklayıcı ardışık desende amaç, nicel yöntemler kullanarak elde edilen verilerin sonuçlarına daha derinlemesine açıklama getirebilmek için nitel yöntemlerinin kullanılmasıdır (Creswell, 2017). Karma yöntem, çevremizdeki olay ve olguların karmaşık olması sebebiyle çok boyutlu olarak açıklanmasına ilham vermektedir (Yıldırım \& Şimşek, 2013).

Araştırmada ilk olarak nicel veriler toplanarak analiz edilmiş ardından nitel veriler toplanarak analiz edilmiştir. Böylelikle ilk aşamada elde edilen nicel veriler, nitel verilerle desteklenerek ayrıntılı biçimde açıklanmıştır. Araştırmanın nicel boyutunda, ortaöğretim öğrencilerinin oyun kavramına ve fiziksel aktivite içeren oyunları oynamaya yönelik tutumlarının bazı değişkenler açısından incelemek için tarama modelinden faydalanılmıştır. Tarama modeli, var olan durumu olduğu şekliyle betimlemeyi amaçlayan araştırma yaklaşımıdır. $\mathrm{Bu}$ model, araştırmaya konu olan olay ya da bireyleri herhangi bir etkileme çabasına girmeden kendi koşulları içerisinde betimlemeye çalışır (Karasar, 2014). Karma yöntemle yürütülen araştırmada, nicel verileri derinlemesine incelemek amacıyla nitel verilerin toplanmasında olgu bilim deseni kullanılmıştır. Olgu bilim deseni diğer adıyla fenomenoloji, günlük hayatta deneyimlediğimiz, farkında olduğumuz ancak derinlemesine ve ayrıntılı bir bilgiye sahip olmadığımız olgulara odaklanan araştırma desenidir ve insanların bu olguları nasıl algıladıkları, nasıl betimledikleri ve bu olgulara ilişkin tutumları ile ilgilidir. (Patton, 2018; Yıldırım \& Şimşek, 2013). Olgu bilim deseni kullanılarak ortaöğretim öğrencilerinin oyun kavramına ve fiziksel aktivite içeren oyunları oynamaya yönelik tutumlarının; yaş, cinsiyet, sınıf, öğrenim görülen okul türü, spor geçmişi, boy ve kilo değerleri ayrıntılı olarak incelenmiştir.

\section{Araştırma Grubu}

Çalışma 2019-2020 eğitim öğretim yılında Gaziantep İl Milli Eğitimi Müdürlüğü’ne bağlı okullarda öğrenim görmekte olan ortaöğretim öğrencileri üzerinde gönüllülük esasına dayalı olarak uygulanmıştır. Çalışmaya 688 öğrenci gönüllü olarak katılmıştır. Eksik veya yanlış doldurulan ölçekler çalışma dışı bırakılmış ve toplam 613 öğrencinin (227 kadın, 386 erkek) doldurduğu ölçekler çalışma kapsamında değerlendirilmiştir. Araştırmaya katılan erkeklerin boy ortalamas1 158.48 , kilo ortalamas1 52.49 , kızların boy ortalamas1 165.09 , kilo ortalamas1 58.41 olarak tespit edilmiştir.

Araştırma grubunun çalışmada ele alınan değişkenlere ait özelliklerin dağılımı tablo 3.1.'de verilmiştir. 
Tablo1. Araştırma grubuna ait kişisel özellikler

\begin{tabular}{|c|c|c|c|}
\hline Değişkenler & Gruplar & $\mathbf{n}$ & $\%$ \\
\hline \multirow[t]{2}{*}{ Cinsiyet } & Erkek & 386 & 63.0 \\
\hline & $\mathrm{K} 1 \mathrm{z}$ & 227 & 37.0 \\
\hline \multirow[t]{5}{*}{ Yaş } & 15 yaş & 107 & 17.45 \\
\hline & 16 yaş & 207 & 33.8 \\
\hline & 17 yaş & 172 & 28.1 \\
\hline & 18 yaş & 106 & 17.3 \\
\hline & 19 yaş & 21 & 3.35 \\
\hline \multirow[t]{4}{*}{ Sinıf } & 9.sinif & 210 & 34.3 \\
\hline & 10. $\sin 1 f$ & 164 & 26.8 \\
\hline & 11.sinif & 173 & 28.2 \\
\hline & 12.sinif & 66 & 10.8 \\
\hline \multirow[t]{2}{*}{ Spor Geçmişi } & Evet & 292 & 47.6 \\
\hline & Hayır & 321 & 52.4 \\
\hline \multirow[t]{5}{*}{ Okul Türü } & Sağlık Meslek & 125 & 20.39 \\
\hline & Anadolu & 147 & 23.98 \\
\hline & Kız Meslek & 94 & 15.33 \\
\hline & Fen & 112 & 18.27 \\
\hline & Ticaret Meslek & 135 & 22.03 \\
\hline
\end{tabular}

\section{Veri Toplama Araçları}

Fiziksel aktivite içeren oyunları oynamaya ilişkin tutum (oyunsallık) ölçeği: Araştırma verilerinin elde edilmesinde kişisel bilgi formu ile Hazar (2015) tarafından geliştirilen Oyunsallık Ölçeği kullanılmıştır. Bu ölçek fiziksel hareketlilik içeren aktif oyunları oynama arzu ve isteğini belirlemek amacıyla hazırlanmıştır. Bu nedenle, fiziksel mücadele eylemleri içeren oyunları ve oynama isteği göz önünde bulundurarak cevaplama istenmektedir. 18-25 yaş grubu üniversite öğrencileri üzerinde yapılan uygulama neticesinde geliştirilen 25 maddeden oluşan 5 faktörlü bir ölçektir. Ölçek 5'li likert tipinde olup, Kesinlikle Katılmiyorum (1), Katılmıyorum (2), Kararsızım (3), Katılıyorum (4), Kesinlikle Katıliyorum (5) şeklinde cevaplardan oluşmaktadır. Oyunsallık ölçeğinin güvenirliği için Cronbach Alfa değeri 0.86 olarak hesaplanmıştır.

Kişisel bilgi formu: Çalışmada birbirinden bağımsız değişkenlere ait veriler, çalışmacının hazırladığ 1 kişisel bilgi formu ile kazanılmıştır. Kişisel bilgi formunda; yaş, cinsiyet, sınıf, öğrenim görülen okul türü, ailenin sosyo-ekonomik düzeyi ile alakalı sorular yer almaktadır (Ek 1).

Görüssme formu: Ortaöğretim öğrencilerinin oyun kavramına ilişkin görüşlerini derinlemesine incelemek amacıyla, 3 maddeden oluşan yarı yapılandırılmış görüşme formu üç uzman görüşü alınarak oluşturulmuştur.

Nitel verilerin toplanması için yapılan görüşmeler gönüllülük esası göz önünde bulundurularak ses kaydı yapılmıştır. Görüşmeler yaklaşık 20 dakika sürmüştür. Nitel verilerin analizinde öncelikle öğrencilerden alınan ses kayıtları bilgisayar ortamında metin haline dönüştürülmüştür. Oluşturulan kodlar, bir liste halinde sıralanarak, kod listesi oluşturulmuştur. Yapılan görüşmelerde katılımcıların ifadelerinden doğrudan alıntılar bulgular bölümünde verilmiştir. 
Yarı yapılandırılmış görüşme formu şu sorulardan oluşmaktadır;

1. Oyun nedir?

2. Oyunun faydaları nelerdir?

3. Okulunuzda bulunan oyun alanlarının yeterliliğine ilişkin görüşleriniz nelerdir?

\section{Verilerin Toplanması}

Çalışmada verileri toplamak amacıyla, 2019-2020 eğitim-öğretim yılında Gaziantep İl Milli Eğitimi Müdürlüğü'ne bağlı okullarda öğrenim görmekte olan 613 ortaöğretim öğrencisine "Oyun Kavramına ve Fiziksel Aktivite İçeren Oyunları Oynamalarına İlişkin Tutum Ölçeği”" uygulanmıştır. Ölçme aracı uygulanmadan önce çalışmanın amacı ölçek ile birlikte gönüllü olarak katılan öğrencilere açıklanmıştır. Araştırmada kullanılan ölçme aracı öğrenciler tarafından yaklaşık 15-20 dakikada uygulanmıştır. Ölçme araçlarının doldurulması esnasında öğrencilerin gönüllü olmasına dikkat edilmiştir.

\section{Verilerin Analizi}

Araştırmada kullanılan ölçeklerden elde edilen veriler bilgisayar ortamına kodlanıp SPSS 20.0 paket programından yararlanılarak istatistiksel analizler yapılmıştır. Araştırma verilerinin normal dağılım gösterip göstermediğini belirlemek amacıyla Kolmogorov-Smirnov normallik testleri yapılmıştır. Normal dağılım göstermeyen veri setleri için Kurtosis-Skewness değerlerine bakılmış ve değerlerin $+2 /-2$ arasında olduğu görülmüş, verilerin normal dağılım gösterdiği belirlenmiştir. Buradan hareketle ikili gruplar için İndependent Samples t testi, çoklu gruplar için One Way ANOVA testi kullanılmıştır. Veriler arasındaki ilişkiyi belirlemek amacıyla Pearson korelasyon analizi kullanılmıştır. Nitel verilerin analizi yapılırken içerik analizi tekniği kullanılmıştır. İçerik analizi, toplanan verileri açıklayabilmek için birbirine benzeyen verileri belirli kavramlar çerçevesinde bir araya getirmek ve bunları okuyucunun anlayacağı biçimde düzenleyerek yorumlamaktır. İçerik analizinde kodlama yapılarak veriler analiz edilebilir. Kodlama, kendi içinde anlamlı bir bütün oluşturan bölümlerin, araştırmacı tarafından tanımlayıcı sözcük ya da sözcük gruplarıyla adlandırılmasıdır (Yıldırım \& Şimşek, 2013).

\section{BULGULAR VE YORUM}

\section{Nicel Bulgular}

$\mathrm{Bu}$ kısımda çalışma grubuna yapılan ölçeklerden elde edilen verilere ilişkin bulgular yer almaktadir.

Tablo 2. Katılımcıların cinsiyet değişkeni açısından oyunsallık puanlarının karşılaştırması

\begin{tabular}{|c|c|c|c|c|c|c|}
\hline & Cinsiyet & $\mathbf{N}$ & Ort. & SS & $\mathbf{t}$ & $\mathbf{p}$ \\
\hline \multirow[t]{2}{*}{ OyunTutkusu } & Erkek & 386 & 3.64 & 0.72 & 4.307 & .000 \\
\hline & $\mathrm{K}_{1 \mathrm{Z}}$ & 227 & 3.13 & 0.91 & & \\
\hline \multirow[t]{2}{*}{ RiskAlma } & Erkek & 386 & 3.01 & 0.82 & 4.671 & .000 \\
\hline & $\mathrm{K}_{1 \mathrm{Z}}$ & 227 & 2.54 & 0.84 & & \\
\hline \multirow[t]{2}{*}{ SosyalUyum } & Erkek & 386 & 2.14 & 0.81 & 1.413 & .471 \\
\hline & $\mathrm{K}_{1 \mathrm{Z}}$ & 227 & 2.19 & 0.89 & & \\
\hline \multirow[t]{2}{*}{ Oyunİsteği } & Erkek & 386 & 2.47 & 0.81 & 2.451 & .004 \\
\hline & $\mathrm{K}_{1 \mathrm{z}}$ & 227 & 2.19 & 0.62 & & \\
\hline \multirow[t]{2}{*}{ KeyifAlma } & Erkek & 386 & 2.62 & 0.89 & 2.111 & .000 \\
\hline & $\mathrm{K}_{1 \mathrm{Z}}$ & 227 & 2.22 & 0.76 & & \\
\hline
\end{tabular}


Tablo 2'de araştırma grubunun cinsiyet değişkeni açısından ölçeğin alt boyutlarından elde ettikleri puanların karşılaştırması verilmektedir. İki grup arasında oyun tutkusu, risk alma, oyun isteği ve keyif alma alt boyutlarında erkekler lehine anlamlı farklılıklara rastlanmıştır $(\mathrm{p}<0.05)$.

Tablo 3. Katılımcıların yaş değiş̧keni açısından oyunsallık puanlarının karşılaştırması

\begin{tabular}{|c|c|c|c|c|c|c|c|}
\hline & & KT & sd & KO & $\mathbf{F}$ & p & Anlamlı Fark \\
\hline Oyun & Gruplar arası & 8.301 & 4 & 1.801 & 2.255 & .022 & $1-4,1-5$ \\
\hline \multirow[t]{2}{*}{ Tutkusu } & Grup içi & 381.653 & 608 & .798 & & & $2-4,2-5$ \\
\hline & Toplam & 376.452 & 612 & & & & \\
\hline \multirow[t]{3}{*}{ Risk Alma } & Gruplar arası & 9.539 & 4 & 2.385 & 2.664 & .032 & $4-1,4-2$ \\
\hline & Grup içi & 436.876 & 608 & .895 & & & $4-3$ \\
\hline & Toplam & 446.414 & 612 & & & & \\
\hline \multirow[t]{3}{*}{ Sosyal Uyum } & Gruplar arası & 9.037 & 4 & 2.321 & 5.013 & .001 & $1-2,1-3$ \\
\hline & Grup içi & 265.732 & 608 & .462 & & & $1-4$ \\
\hline & Toplam & 286.365 & 612 & & & & \\
\hline \multirow[t]{3}{*}{ Oyun İsteği } & Gruplar arası & 2.346 & 4 & .583 & 4.153 & .003 & $1-4,1-5$ \\
\hline & Grup içi & 281.223 & 608 & .571 & & & $2-4,2-5$ \\
\hline & Toplam & 286.387 & 612 & & & & \\
\hline \multirow[t]{3}{*}{ Keyif Alma } & Gruplar arası & 1.315 & 4 & .316 & .496 & .765 & \\
\hline & Grup içi & 313.405 & 608 & .621 & & & \\
\hline & Toplam & 319.514 & 612 & & & & \\
\hline
\end{tabular}

Gruplar; 1. grup 15 yaş, 2. grup 16 yaş, 3 . grup 17 yaş, 4 . grup 18 yaş, 5 . grup 19 yaş

Tablo 3'te öğrencilerin yaş değişkeni açısından ölçeğin alt boyutlardan elde ettikleri puanların karşılaştırması verilmektedir. Buna göre ölçeğin oyun tutkusu, risk alma, sosyal uyum ve oyun isteği alt boyutlarında anlamlı farklılığa rastlanmıştır. Anlamlı farklılığın hangi gruplar arasında olduğunu belirlemek amaciyla yapılan LSD testi sonuçlarına göre;

Oyun tutkusu ve oyun isteği alt boyutlarında 15-16 yaş grubunda olanların 18-19 yaş grubunda olanlardan daha yüksek puan elde ettikleri tespit edilmiştir.

Risk alma alt boyutunda, 18 yaşında olanların elde ettiği puanların 15, 16 ve 17 yaş grubunda olanlardan daha yüksek olduğu tespit edilmiştir.

Sosyal uyum alt boyutunda 15 yaşında olanların elde ettiği puanların 16, 17 ve 18 yaş grubunda olanlardan daha yüksek olduğu tespit edilmiştir. 
E. YELTEKIN \&

F. ALINCAK
Ortaöğretim Öğrencilerinin Oyun Kavramına ve Fiziksel Aktivite İçeren Oyunları Oynamaya Yönelik Tutumlarının Bazı Değişkenler Açısından İncelenmesi

Tablo 4. Katılımcıların sınıf değişkeni açısından oyunsallık puanlarının karşılaştırması

\begin{tabular}{|c|c|c|c|c|c|c|c|}
\hline & & KT & sd & KO & $\mathbf{F}$ & $\mathbf{p}$ & $\begin{array}{c}\text { Anlamlı } \\
\text { Fark }\end{array}$ \\
\hline \multirow[t]{3}{*}{ Oyun Tutkusu } & Gruplar arası & 6.963 & 3 & 2.441 & 3,726 & .004 & $1-5$ \\
\hline & Grup içi & 379.851 & 609 & .693 & & & $2-5$ \\
\hline & Toplam & 385.767 & 612 & & & & \\
\hline \multirow[t]{3}{*}{ Risk Alma } & Gruplar arası & 8.652 & 3 & 2.990 & 4.521 & .000 & $4-1$ \\
\hline & Grup içi & 431,425 & 609 & .895 & & & $4-2$ \\
\hline & Toplam & 441,562 & 612 & & & & $4-3$ \\
\hline \multirow[t]{3}{*}{ Sosyal Uyum } & Gruplar arası & 4,123 & 3 & 1.307 & 3.436 & .006 & $1-2$ \\
\hline & Grup içi & 228,035 & 609 & .460 & & & $1-3$ \\
\hline & Toplam & 234,563 & 612 & & & & $1-4$ \\
\hline \multirow[t]{3}{*}{ Oyun İsteği } & Gruplar arası & 3,845 & 3 & 1.137 & 4,178 & .003 & $1-5$ \\
\hline & Grup içi & 283,697 & 609 & .567 & & & $2-5$ \\
\hline & Toplam & 291,321 & 612 & & & & \\
\hline \multirow[t]{3}{*}{ Keyif Alma } & Gruplar arası & 3,021 & 3 & .986 & 1.318 & .265 & \\
\hline & Grup içi & 325.542 & 609 & .613 & & & \\
\hline & Toplam & 336.287 & 612 & & & & \\
\hline
\end{tabular}

Gruplar; 9. sinif, 10. sinif, 11. sinif, 12. sinif

Tablo 4'te öğrencilerin sınıf değişkeni açısından ölçeğin alt boyutlarından elde ettikleri puanların karşılaştırması verilmektedir. Buna göre ölçeğin oyun tutkusu, risk alma ve sosyal uyum alt boyutlarında anlamlı farklılığa rastlanmıştır. Anlamlı farklılığın hangi gruplar arasında olduğunu belirlemek amacıyla yapılan Tukey LSD testi sonuçlarına göre;

Oyun tutkusu ve oyun isteği alt boyutunda, 9. ve 10. sınıfta olanların 12. sinıfta olan gruplardan daha yüksek puanlar elde ettikleri tespit edilmiştir.

Risk alma alt boyutunda, 11. sınıfta olanların 9 ve 10. sinıfta olanlardan daha yüksek puanlar elde ettiği tespit edilmiştir.

Sosyal uyum alt boyutunda, 9. sinifta olanların 10 ve 11. sinıfta olanlardan daha yüksek puan elde ettikleri tespit edilmiştir.

Tablo 5. Katılımcıların spor yapma geçmişi değişkeni açısından oyunsallık puanlarının karşılaştırması

\begin{tabular}{|c|c|c|c|c|c|c|}
\hline & Spor Geçmişi & $\mathbf{N}$ & Ort. & SS & $\mathbf{t}$ & $\mathbf{p}$ \\
\hline \multirow[t]{2}{*}{ Oyun Tutkusu } & Hayır & 321 & 3,12 & 0.89 & -2.687 & .002 \\
\hline & Evet & 292 & 3.46 & 0.85 & & \\
\hline \multirow[t]{2}{*}{ Risk Alma } & Hayır & 321 & 2.83 & 0.91 & -4.318 & .000 \\
\hline & Evet & 292 & 3.01 & 0.89 & & \\
\hline \multirow[t]{2}{*}{ Sosyal Uyum } & Hayır & 321 & 1.63 & 0.65 & -2.452 & .002 \\
\hline & Evet & 292 & 2.23 & 0.67 & & \\
\hline \multirow[t]{2}{*}{ Oyun İsteği } & Hayır & 321 & 2.16 & 0.69 & -4.131 & .000 \\
\hline & Evet & 292 & 2.44 & 0.75 & & \\
\hline \multirow[t]{2}{*}{ Keyif Alma } & Hayır & 321 & 2.23 & 0.73 & -3.623 & .000 \\
\hline & Evet & 292 & 2.48 & 0.76 & & \\
\hline
\end{tabular}

Tablo 5'te araştırma grubunun spor geçmişi değişkeni açısından ölçeğin alt boyutlarından elde ettikleri puanların karşılaştırması verilmektedir. İki grup arasında risk alma, sosyal uyum, oyun isteği ve keyif alma alt boyutlarında spor geçmişi olanlar lehine anlamlı farklılıklara rastlanmıştır $(\mathrm{p}<0.05)$. 
E. YELTEKIN \&

F. ALINCAK
Ortaöğretim Öğrencilerinin Oyun Kavramına ve Fiziksel Aktivite İçeren Oyunları Oynamaya Yönelik Tutumlarının Bazı Değişkenler Açısından İncelenmesi

Tablo 6. Katılımcıların öğrenim gördüğü okul türü değişkeni açısından oyunsallık puanlarının karşılaştırması

\begin{tabular}{|c|c|c|c|c|c|c|c|}
\hline & & KT & sd & KO & $\mathbf{F}$ & $\mathbf{p}$ & $\begin{array}{c}\text { Anlamlı } \\
\text { Fark }\end{array}$ \\
\hline \multirow[t]{3}{*}{ OyunTutkusu } & Gruplar arası & 4.541 & 4 & 1.214 & 1.365 & .124 & \\
\hline & Grup içi & 393.118 & 608 & .701 & & & \\
\hline & Toplam & 398.457 & 612 & & & & \\
\hline \multirow[t]{3}{*}{ RiskAlma } & Gruplar arası & 2.529 & 4 & .632 & .845 & .402 & \\
\hline & Grup içi & 447.594 & 608 & .874 & & & \\
\hline & Toplam & 451.341 & 612 & & & & \\
\hline \multirow[t]{3}{*}{ SosyalUyum } & Gruplar arası & 7.416 & 4 & 1.875 & 4.874 & .000 & $2-1,2-3$ \\
\hline & Grup içi & 223.121 & 608 & .632 & & & $2-5$ \\
\hline & Toplam & 231.947 & 612 & & & & $3-1,3-5$ \\
\hline \multirow[t]{3}{*}{ Oyunİsteği } & Gruplar arası & 4.225 & 4 & 1.254 & 1.423 & .351 & \\
\hline & Grup içi & 267.279 & 608 & .612 & & & \\
\hline & Toplam & 273.457 & 612 & & & & \\
\hline \multirow[t]{3}{*}{ KeyifAlma } & Gruplar arası & 3.763 & 4 & 1.124 & 1.862 & .082 & \\
\hline & Grup içi & 291.815 & 608 & .663 & & & \\
\hline & Toplam & 296.467 & 612 & & & & \\
\hline
\end{tabular}

Gruplar; 1. grup Sağlık Meslek, 2. grup Anadolu, 3. grup Kız Meslek, 4. grup Fen, 5. grup Ticaret Meslek

Tablo 6'da öğrencilerin okul türü değişkeni açısından ölçeğin alt boyutlarından elde ettikleri puanların karşılaştırması verilmektedir. Buna göre ölçeğin sosyal uyum alt boyutunda Anadolu ve Fen Lisesinde öğrenim görenler lehine anlamlı farklılığa rastlanmıştır $(p<0.05)$.

Tablo 7. Katılımcıların kilo değerleri ile oyunsallık ölçeğinden elde ettikleri puanlar arasındaki ilişki

\begin{tabular}{lcc}
\hline Alt Boyutlar & & Kilo \\
\hline Oyun Tutkusu & $\mathrm{r}$ & -.696 \\
& $\mathrm{p}$ & .000 \\
& $\mathrm{n}$ & 613 \\
\hline Risk Alma & $\mathrm{r}$ &, 004 \\
& $\mathrm{p}$ &, 928 \\
\hline Sosyal Uyum & $\mathrm{n}$ & 613 \\
\hline Oyun İsteği & $\mathrm{r}$ &, 021 \\
& $\mathrm{p}$ &, 603 \\
& $\mathrm{n}$ & 613 \\
\hline Keyif Alma & $\mathrm{r}$ & -.655 \\
& $\mathrm{p}$ & .000 \\
& $\mathrm{n}$ & -.613 \\
\hline
\end{tabular}

Tablo 7' de araştırma grubunun kilo değerleri ile oyunsallık ölçeğinden elde ettikleri puanlar arasındaki ilişki verilmektedir. Yapılan analize göre, kilo ile oyun tutkusu, oyun isteği ve keyif alma alt boyutları arasında orta düzeyde negatif ilişkilere rastlanmıştır. Dolayısıyla kilonun arttığı durumlarda oyun tutkusu, oyun isteği ve keyif alma düzeylerinin azaldığından söz edilebilir. 
Tablo 8. Katılımcıların boy değerleri ile oyunsallık ölçeğinden elde ettikleri puanlar arasındaki ilişki

\begin{tabular}{lcc}
\hline Alt Boyutlar & & Boy \\
\hline Oyun Tutkusu & $\mathrm{r}$ &,- 063 \\
& $\mathrm{p}$ &, 118 \\
& $\mathrm{n}$ & 613 \\
\hline Risk Alma & $\mathrm{r}$ &,- 065 \\
& $\mathrm{p}$ &, 110 \\
& $\mathrm{n}$ & 613 \\
\hline Sosyal Uyum & $\mathrm{r}$ &, 009 \\
& $\mathrm{p}$ &, 824 \\
& $\mathrm{n}$ & 613 \\
\hline Oyun İsteği & $\mathrm{r}$ &,- 025 \\
& $\mathrm{p}$ &, 539 \\
& $\mathrm{n}$ & 613 \\
\hline Keyif Alma & $\mathrm{r}$ &,- 039 \\
& $\mathrm{p}$ &, 336 \\
& $\mathrm{n}$ & 613 \\
\hline
\end{tabular}

Tablo 8' de araştırma grubunun boy değerleri ile oyunsallık ölçeğinden elde ettikleri puanlar arasındaki ilişki verilmektedir. Yapılan analize göre, ortaöğretim öğrencilerinin boy değerleri ile oyunsallık ölçeği alt boyutlarından elde ettikleri puanlar arasında herhangi bir ilişkiye rastlanamamıştır.

\section{Nitel Bulgular}

$\mathrm{Bu}$ kısımda çalışma grubu ile yapılan görüşmeler sonrası elde edilen verilere ilişkin bulgular yer almaktadir.

Tablo 9. Katılıcıların oyun kavramına ilişkin görüşlerinin dağılımı

\begin{tabular}{lcc}
\hline Temalar & n & \% \\
\hline Kendini tanımadır & 35 & 10.4 \\
Öğrenmenin ilk adımıdır & 33 & 9.9 \\
Keyif ve mutluluktur & 32 & 9.5 \\
Eğlenmedir & 32 & 9.5 \\
İhtiyaçtır & 30 & 8.9 \\
İletişim aracıdır & 30 & 8.9 \\
Gerçek hayata hazırlıktır & 28 & 8.3 \\
Kişilik kazanmadır & 26 & 7.7 \\
Sosyalleşmedir & 24 & 7.1 \\
Özgüvendir & 23 & 6.8 \\
Deneyimdir & 22 & 6.5 \\
Paylaşmadır & 22 & 6.5 \\
\hline Toplam & $\mathbf{3 3 7}$ & $\mathbf{1 0 0}$ \\
\hline
\end{tabular}

Tablo 9'da çalışmaya katılan ortaöğretim öğrencilerinin oyun kavramına ilişkin görüşleri incelendiğinde, \%10.4'ü kendini tanımak, \%9.9'u öğrenmenin ilk adımı, \%9.5'i keyif ve mutluluk, \%9.5'i eğlenmek olduğunu belirtmişlerdir. Ayrıca çalışmaya katılan öğrenciler oyunun; \%8.9'u ihtiyaç, \%8.9'u iletişim aracı, \%8.3'ü gerçek hayata hazırlık, \%7.7'isi kişilik kazanma, \%7.1'i ise sosyalleşme olduğu yönünde görüş bildirmişlerdir. Bunun yanında araştırmaya katılan ortaöğretim öğrencilerinin bazıları ise oyunun; \%6.8'i özgüven, \%6.5'i deneyim, \%6.5'i paylaşma olduğunu ifade etmişlerdir. Katılımcıların birden fazla görüş ifade ettikleri görülmüştür. 
Tablo 10. Katılımcıların oyununun faydalarına ilişkin görüşlerinin dağılımı

\begin{tabular}{lcc}
\hline Temalar & n & \% \\
\hline Faydalı & 33 & 20.4 \\
Öğrenme sürecimizi daha hızlı ve kolay olmakta & 32 & 19.7 \\
Yaparak ve yaşayarak öğrenme imkânı sağlamakta & 26 & 16.1 \\
Kendimizi ifade etmemizde yararlı & 25 & 15.4 \\
Yaratıcılığımızı arttırmakta & 23 & 14.2 \\
Dikkat ve motivasyonumuzu artmakta & 23 & 14.2 \\
\hline Toplam & $\mathbf{1 6 2}$ & $\mathbf{1 0 0}$ \\
\hline
\end{tabular}

Tablo 10'da çalışmaya katılan ortaöğretim öğrencilerinin oyunun faydalarına ilişkin görüşleri incelendiğinde, \%20.4'ü oyunun faydalı olduğunu, \%19.7'si öğrenme sürecinin daha hızlı ve kolay olduğunu, \%16.1'i, yaparak ve yaşayarak öğrenme imkânı sağladığını belirtmişlerdir. Bunun yanında araştırmaya katılan ortaöğretim öğrencileri oyunun; kendilerini ifade etmesinde etkili olduğu, yaratıcılıklarını arttırdığını, dikkat ve motivasyonunu arttırdığ yönünde görüş ifade etmişlerdir. Katılımcıların birden fazla görüş ifade ettikleri görülmüştür.

Tablo 11. Katılımcıların okullarında bulunan oyun alanlarının yeterliliğine ilişkin görüşlerinin dağılımı

\begin{tabular}{lcc}
\hline Temalar & n & \% \\
\hline Oyun alanları yeterli değil & 32 & 64 \\
Alan olarak kısmen yeterli & 12 & 24 \\
Oyun alanları yeterli & 6 & 12 \\
\hline Toplam & $\mathbf{5 0}$ & $\mathbf{1 0 0}$ \\
\hline
\end{tabular}

Tablo 11'de çalışmaya katılan ortaöğretim öğrencilerinin okullarında bulunan oyun alanlarının yeterliliğine ilişkin görüşleri incelendiğinde \%64'ü oyun alanlarının yeterli olmadığ1 yönünde görüş bildirirken, \%24'ü ise oyun alanlarının kısmet yeterli olduğunu belirtmiştir. Çalışmaya katılan 6 öğrenci ise oyun alanlarının yeterli olduğunu ifade etmiştir.

\section{TARTIŞMA VE SONUÇ}

Ortaöğretim öğrencilerinin oyun kavramına ve fiziksel aktivite içeren oyunları oynamaya yönelik tutumlarını incelemek amacıyla yapılan çalışmanın bu bölümünde, araştırmanın genel amaçları çerçevesinde hazırlanan, alt problemler ve bu problemlere yönelik ortaya çıkan bulgulara ait yorumlar ve tartışmalar yapılmıştır. Ayrıca, alan yazında bu araştırmanın bulguları ile benzerlik ya da farklılık gösteren çeşitli araştırma sonuçları irdelenmiş ve bu konuda tartışmalara yer verilmiştir.

Cinsiyet değişkeni açısından, çalışma grubunun fiziksel aktivite içeren oyunları oynamaya yönelik tutumlarında; oyun tutkusu, risk alma, oyun isteği ve keyif alma alt boyutlarında erkekler lehine anlamlı farklılıklara rastlanırken, erkeklerin kadınların daha yüksek puanlara sahip olduğu görülmektedir. Dolayısıyla erkek öğrencilerin fiziksel aktivite içeren oyunlara yönelik tutumlarının daha yüksek olduğunu belirtebiliriz. Bu sonuç erkeklerin fiziksel aktivite düzeylerinin daha fazla olmasından kaynaklanabilir.

Zira yapılan birçok çalışmada erkeklerin fiziksel aktivite düzeylerinin daha fazla olduğu belirtilmektedir (Acree \& diğ., 2006; Genç \& di ̆. ., 2011; Vural \& diğ., 2010). Alıncak vd. (2018) çalışmasında erkek öğrencilerin, oyun tutkusu, risk alma, oyun isteği ve keyif alma alt boyutlarında anlamlı olarak yüksek puanlar elde ettiklerini belirtmiştir. 
Alıncak (2016) ortaokul öğrencilerinin fiziksel aktivite içeren oyunları oynamaya yönelik tutumları üzerine yaptığı araştırmada genel manada pozitif yönde anlamlı ilişkilere rastlandığ sonucuna ulaşmıştır. Bunun yanında öğrencilerin sportif aktivitelerde yer almasının nedenleri içerisinde arkadaşlarının ve sosyal çevrenin etken olduğu yönünde görüş ifade etmiştir. Yıldırım ve arkadaşları (2006) ise araştırmalarında öğrencilerin spor yapmalarında keyif alma ve sporu sevmenin etken olduğunu ifade etmişlerdir.

Risk alma tutumuna yönelik yapılan araştırmalarda kızlara göre, erkeklerin daha çok risk alma davranışı gösterdiği sonucuna birçok çalışmada ulaşılmıştır (Gülgez \& Kısaç, 2013; Marcus, 1999; Morsünbül, 2014; Uludağlı \& Sayıl, 2009). Erkek ve kadınların toplumsallaşma süreçleri farklılık gösterdiğinden, erkeklerin kızlara göre daha riskli davranma eğiliminde olduğu belirtilmektedir (Chen \& diğ., 1998). Öztürk (2016) tarafından spor bilimleri öğrencileri üzerinde yapılan çalışmada oyun tutkusu ve risk alma alt boyutlarında farklılık görülmemiştir. Bu sonuç her iki cinsiyetinde spor ile uğraşmalarından kaynaklanabilir.

Yaş değişkeni açısından, araştırmaya katılan öğrencilerin fiziksel aktivite içeren oyunları oynamaya yönelik tutumlarında; oyun tutkusu, risk alma, sosyal uyum ve oyun isteği alt boyutlarında anlamlı farklılığa rastlanmıştır. Anlamlı farklılığın hangi gruplar arasında olduğunu belirlemek amacıyla yapılan LSD testi sonuçlarına göre; oyun tutkusu ve oyun isteği alt boyutlarında 15-16 yaş grubunda olanların 18-19 yaş grubunda olanlardan daha yüksek puan elde ettikleri tespit edilmiştir. Risk alma alt boyutunda, 18 yaşında olanların elde ettiği puanların 15, 16 ve 17 yaş grubunda olanlardan daha yüksek olduğu görülmüştür. Sosyal uyum alt boyutunda 15 yaşında olanların elde ettiği puanların 16, 17 ve 18 yaş grubunda olanlardan daha yüksek olduğu ortaya çıkmıştır.

Hacıcaferoğlu ve Öztürk (2020) çalışmalarında yaş değişkeni açısından; 18-19 ile 22 yaş gruplarında olan adayların fiziksel aktivite içeren oyunların sosyal uyum sağlamada daha fazla katkı sağladığı, 20-21 yaş gurubunda olan katılımcıların ise keyif alma durumuna katk1 sağladığı yönünde sonuca ulaşmışlardır.

Ayrıca yapılan farklı çalışmalara bakıldığında yaş oranlarının arttığı evrelerde fiziksel aktiviteyi daha çok sağlık amaçlı gerçekleştiren araştırma sonuçlarının olduğu görülmektedir (Arabacı \& Çankaya, 2007; Hallal \& diğ., 2000).

Sınıf değişkeni açısından araştırma grubunun; fiziksel aktivite içeren oyunları oynamaya yönelik tutumlarının; oyun tutkusu, risk alma ve sosyal uyum alt boyutlarında anlamlı farklılığa rastlanmıştır. Anlamlı farklılığın hangi gruplar arasında olduğunu belirlemek amacıyla yapılan Tukey LSD testi sonuçlarına göre; oyun tutkusu ve oyun isteği alt boyutunda, 9. ve 10. sinıfta olanların 12. Sinıfta olan gruplardan daha yüksek puanlar elde ettikleri görülmüştür. Risk alma alt boyutunda, 11. sınıfta olanların 9 ve 10. sinıfta olanlardan daha yüksek puanlar elde ettiği ifade edilmiştir. Sosyal uyum alt boyutunda, 9. sinıfta olanların 10 ve 11. sinıfta olanlardan daha yüksek puan elde ettikleri görülmüştür.

Alıncak ve arkadaşları (2018) ortaokul öğrencileri üzerine yaptığı çalışmasında öğrencilerin; oyun tutkusu ve sosyal uyum alt boyutlarında anlamlı farklılıklara rastlanmıştır. Oyun tutkusu alt boyutunda birinci sınıf düzeyinde öğrenim gören öğrencilerin elde ettikleri puanların diğer sınıf gruplarına göre daha yüksek olduğu sonucuna ulaşmıştır. 
Ayrıca Alıncak (2016) sınıf öğretmeni adayları üzerine yapmış olduğu çalışmasında; oyun tutkusu ve sosyal uyum alt boyutlarında anlamlı farklılıklara rastlanmıştır. Oyun tutkusu alt boyutunda birinci sınıf düzeyinde öğrenim görenlerin elde ettikleri puanların daha yüksek olduğu sonucuna ulaşılmıştı. Bunun nedeninin ise, birinci sınıf düzeyinde öğrenim görenlerin üniversite öğrenimlerine yeni başlamış olmalarıyla birlikte yaşlarının daha küçük olmasının etkisinin olduğu söylenebilir.

Spor geçmişi değişkeni açısından araştırma grubunun; fiziksel aktivite içeren oyunları oynamaya yönelik tutum puanlarında risk alma, sosyal uyum, oyun isteği ve keyif alma alt boyutlarında spor geçmişi olanlar lehine anlamlı farklılıklara rastlanmıştır Buna göre spor geçmişi olan öğrencilerin fiziksel aktivite içeren oyunlara yönelik tutumlarının daha olumlu olduğu söylenebilir.

Konu ile ilgili olarak yapılan farklı çalışmalarda erken yaşlardan itibaren başlanılan fiziksel hareket yaşam boyu spor etkinliklerine dönüştürüldüğünde sağlık üzerine olan etkilerinin de artacağı yönünde sonuçlara ulaşılmıştır. Dolayısıyla küçük yaşlardan itibaren oyun ve fiziksel aktivitenin içerisinde olunmasının sağlık ve gelişim açısından katkı sağlayacağı söylenebilir (Ehrman vd., 2005; Heyward, 2006).

Öğrenim görülen okul türü değişkeni açısından araştırma grubunun fiziksel aktivite içeren oyunları oynamaya yönelik tutum puanları alt boyutlarında ölçeğin sosyal uyum alt boyutunda Anadolu ve Fen Lisesinde öğrenim görenler lehine anlamlı farklılığa rastlanmıştır.

Alıncak ve arkadaşları (2018) öğrenim gördükleri okul türü değişkeni açısından sosyal uyum alt boyutunda Anadolu ve Fen Lisesi öğrencilerinin sağlik, ticaret ve kız meslek lisesi öğrencilerine göre daha yüksek sosyal uyum tutumları olduğunu belirtmişlerdir.

Kilo değerleri açısından araştırma grubunun fiziksel aktivite içeren oyunları oynamaya yönelik tutum puanlarında kilo ile oyun tutkusu, oyun isteği ve keyif alma alt boyutları arasında orta düzeyde negatif ilişkilere rastlanmıştır. Dolayısıyla kilonun arttığı durumlarda oyun tutkusu, oyun isteği ve keyif alma düzeylerinin azaldığından söz edilebilir.

Boy değerleri açısından araştırma grubunun fiziksel aktivite içeren oyunları oynamaya yönelik tutum puanlarında ortaöğretim öğrencilerinin boy değerleri ile oyunsallık ölçeği alt boyutlarından elde ettikleri puanlar arasında herhangi bir ilişkiye rastlanamamıştır.

Çalışmaya katılan ortaöğretim öğrencilerinin oyun kavramına ilişkin görüşleri incelendiğinde; kendini tanımak, öğrenmenin ilk adımı, keyif ve mutluluk, eğlenmek temalarının ön plana çıktığ1 görülmüştür. Ayrıca oyun kavramına ilişkin olarak araştırma grubu; ihtiyaç, iletişim aracı, gerçek hayata hazırlık, kişilik kazanma, sosyalleşme özgüven, deneyim ve paylaşma olduğu yönünde görüş ifade ettikleri görülmüştür. Buradan hareketle genel anlamda oyunun birçok anlamda katkı sağladığını söyleyebiliriz. Özellikle kendilerini tanıma ve eğlenmelerinde etkilerinin olduğu ifade edilebilir.

Uğurel ve Moralı (2008)'nın araştırmasında, genel anlamda oyunun kişinin gerek eğitim hayatında gerekse de özel olarak matematik öğretiminde önemli bir öğrenme ve öğretme aracı olduğu yönünde görüş bildirmiştir. 
Çocukların fiziksel, bilişsel, duyuşsal ve sosyal gelişiminde oyunların önemli bir yeri vardır. Oyunlar, çocuğun çevresini keşfetmesini, karşılaştığı sorunlara çözümler üretmesini ve temel bilgi dağarcığını geliştirmesini sağlayan araçlardır. Çocuk oyun yoluyla, büyüklük, şekil, renk, boyut, ağırlık, hacim, ölçme, sayma, zaman, mekân, uzaklık gibi birçok kavramı öğrenebilir. Oyunlar aynı zamanda bireylerin gönüllü olarak katıldıkları, hoşça zaman geçirdikleri özgür ortamlar sunar çocuklara (Aksoy \& Çiftçi, 2018; Gökçearslan \& Durakoğlu, 2014; Kaya, 2013).

Çalışmaya katılan ortaöğretim öğrencilerinin oyunun faydalarına ilişkin görüşleri incelendiğinde çoğunluğu oyunun faydalı olduğunu belirtmiştir. Ayrıca öğrenciler oyunun faydalarına ilişkin olarak; öğrenme sürecinin daha hızlı ve kolay olduğunu, yaparak ve yaşayarak öğrenme imkânı sağladığını ifade etmişlerdir. Bunun yanında araştırmaya katılan ortaöğretim öğrencileri oyunun; kendilerini ifade etmesinde etkili olduğu, yaratıcılıklarını arttırdığını, dikkat ve motivasyonunu arttırdığı yönünde görüş ifade etmişlerdir. Savaş ve Gülüm (2014) çalışmasında oyunla eğitim yöntemi ile yapılan dersin içeriğinin hatırlanma oranları yüksek olduğu sonucuna ulaşmıştır.

Çalışmaya katılan ortaöğretim öğrencilerinin okullarında bulunan oyun alanlarının yeterliliğine ilişkin görüşleri incelendiğinde büyük bir oranı oyun alanlarının yeterli olmadığ1 yönünde görüş bildirirken, bazıları ise oyun alanlarının kısmet yeterli olduğunu belirtmiştir. Çalışmaya katılan 6 öğrenci ise oyun alanlarının yeterli olduğunu ifade etmiştir.

Yapılan farklı çalışmalarda okullarda bulunan oyun alanlarının yeterli ve güvenli olmadığı sonucuna ulaşılmıştır (Alıncak vd., 2018; Ekinci vd., 2019).

Sonuç olarak, erkeklerin kadınlardan daha yüksek oyunsallık eğilimleri olduğu, yaş ve sınıf değişkenleri açısından küçük yaş ve sınıf gruplarının oyunsallık puanlarının daha yüksek olduğu, spor geçmişi olan öğrencilerin fiziksel aktivite içeren oyunlara yönelik tutumlarının daha olumlu olduğu, Anadolu ve Fen Lisesi öğrencilerinin sosyal uyum alt boyutu puanlarının daha yüksek olduğu sonucuna ulaşılmıştır. Ayrıca, kilonun arttı̆g 1 durumlarda oyun tutkusu, oyun isteği ve keyif alma düzeylerinin azaldığı belirlenirken, boy ile ilgili herhangi bir ilişki bulunamamıştır. Çalışmaya katılan öğrencilerin oyun kavramına ilişkin görüşlerinde kendini tanımak, öğrenmenin ilk adımı, keyif ve mutluluk, eğlenmek temalarının ön plana çıktığı, oyunun faydalarına ilişkin görüşleri incelendiğinde çoğunluğu oyunun faydalı olduğunu, ancak okul ortamında oyun alanlarının yeterli olmadığı yönünde sonuçlara ulaşılmıştır.

\section{Öneriler}

- Yapılan bu sonuçları Gaziantep ilindeki farklı okullarda öğrenim görmekte olan ortaöğretim öğrencilerinden rastgele seçilmiş olan ve araştırmaya gönüllü olarak yarar sağlayan örneklem grubu ile elde edilmiştir, bu örneklem daha da genişletebilir.

- Aynı araştırma farklı illerde öğrenim lise, ortaokul ve ilkokullarda öğrenim gören öğrenciler üzerinde de yapılarak karşılaştırılabilir.

- Aynı araştırma üniversitelerin farklı bölümlerinde öğrenim gören öğrenciler üzerinde yapılarak karşılaştırılabilir.

- Aynı araştırma spor bilimleri fakültelerinin farklı bölümlerinde öğrenim gören öğrenciler üzerinde yapılarak karşılaştırılabilir. 
- Farklı branşlardaki sporculara uygulayıp sporcular ve beden eğitimi ve spor yüksekokulu öğrencileri arasında karşılaştırma yapılmasının da faydalı olacağı düşünülmektedir.

- Daha küçük yaş gruplarında da çalışmanın yapılmasının fayda sağlayacağı düşünülmektedir.

\section{KAYNAKÇA}

Aksoy, A.B., Çiftçi, H.D. (2018). Erken çocukluk döneminde oyun: Duyu-motor oyundan kurallı oyuna. Pegem Akademi.

Alincak, F. (2016). Attitudes of secondary school students including physical activity involving playing games. European Journal of Physical Education and Sport Science, 2(3), 1-14.

Alıncak, F., Abakay, U., Buğdaycı, S. (2018). Examining the attitudes of high school students regarding playing games with physical activity. The Online Journal of Recreation and Sport, 7(2), 40-58.

Alıncak, F., Öztürk, M., Turak, T. (2018). Pedagogical expectances from the playgrounds in the school gardens in classroom teachers. The Online Journal of Recreation and Sports, 7(4), 9-22.

Arabacı, R., Çankaya, C. (2007). Beden eğitimi öğretmenlerinin fiziksel aktivite düzeylerinin araştırılması. Uludă̆ üniversitesi Ĕgitim Fakültesi Dergisi, 20(1), 1-15.

Ayan, S. (2007). Illköğretim I. ve II. Kademede Beden Eğitimi Dersinin Amaçlarına Göre Uygulanma Durumunun İncelenmesi [Yayımlanmamış doktora tezi]. Gazi Üniversitesi.

Ayan, S., Dündar, H. (2009). Eğitimde okulöncesi yaratıcılığın ve oyunun önemi. Selçuk Üniversitesi Ahmet Keleşoğlu Ĕ̈itim Fakültesi Dergisi, 28(1), 63-74.

Barnett, L. A., Storm, B. (1981). Play, pleasure, and pain: The reduction of anxiety through play. Leisure Sciences, 4(2), 161-175.

Chen, C., Grenberger, E., Lester, J., Dong, Q., Guo, M.S. (1998). A cross cultural study of family and peer correlates of adolescent misconduct. Developmental Psychology, 34, 770-781.

Creswell, J., Plano Clark, V.L. (2007) Understanding Mixed Methods Research. In J. Creswell (Ed.), Designing and conducting mixed methods research thousand. Sage.

Creswell, J.W. (2017). Karma yöntem araştırmalarına girişs. Pegem Akademi.

Ehrman, J.K., Gordon. P.M., Visich, P.S. (2005). Clinical exercise physiology (2nd ed.). Human Kinetics Publishers.

Ekinci, N.E., Yalcin, I., Ayhan, C. (2019). Analysis of loneliness levels and digital game addiction of middle school students according to various variables. World Journal of Education,9(1), 20-27.

Genç, A., Şener, Ü., Karabacak, H., Üçok, K. (2011). Kadın ve erkek genç erişkinler arasında fiziksel aktivite ve yaşam kalitesi farklı1ıklarının araştırılması. Kocatepe Tip Dergisi, 12(3), 145-150.

Gonzalez J, Field T, Yando R, Gonzalez K, Lasko D, Bendell D. (1994). Adolescent perceptions of their risktaking behavior. Adolescence, 29(115), 701-709.

Gökçearslan, Ş., Durakoğlu, A. (2014). Ortaokul öğrencilerinin bilgisayar oyunu bağımlılık düzeylerinin çeşitli değişkenlere göre incelenmesi. Dicle Üniversitesi Ziya Gökalp Ĕgitim Fakültesi Dergisi, 23(14), 419435 .

Gülgez, Ö.E., Kısaç, İ. (2014). Lise öğrencilerinin olumsuz risk alma davranışlarının yaş, cinsiyet ve psikolojik belirtiler değişkenleri açısından incelenmesi. Gazi Üniversitesi Endüstriyel Sanatlar Eğitim Fakültesi Dergisi, 33, 122-136.

Hacıcaferoğlu, S., Öztürk, H. (2020). Beden eğitimi ve spor yüksekokulunda eğitim almak isteyen aday öğrencilerin fiziksel aktivite içeren oyunları oynamaya yönelik tutumlarının incelenmesi. Journal of Social and Humanities Sciences Research, 7(57), 2200-2206. 
Hallal, P.C., Victora, C.G., Wells, J.C., Lima, R.C (2000). Physical inactivity: Prevalence and associated variables in brazilian adults. Med Sci Sports Exerc, 35(1), 1894-900.

Hazar, M. (2015). A study of developing an attitudes scale of 18-22 age adults for playing games that contain physical activity (Improving the 18-22 age playing games scale). Niğde University Journal of Physical Education and Sport Sciences, 9(1), 149-162.

Hazar, M. (2000). Beden ĕgitimi ve sporda oyunla ĕgitim. Tutibay.

Heyward, V.H. (2006). Advanced fitness assessment and exercise prescription (5th ed.). Human Kinetics.

İlhan, L. (2010). Hareketsiz yaşamlar kültürü ve beraberinde getirdikleri. Verimlilik Dergisi, 10(3), 195-210.

Jelalia, E., Sipirito, A., Rasile, D., Vinnick, L., Rohrbeck, C., Arrigan, M. (1997). Risk taking, reported injury and perception of future injury among adolescents. Journal of Pediatric Psychology, 22, 513-531.

Karasar, N. (2014). Bilimsel araştırma yöntemi. Nobel Yayın Dağıtım.

Kaya, B.A. (2013). Çevrimiçi oyun bağımlılı̆̆ı ölçeğinin geliştirilmesi [Yayımlanmamış yüksek lisans tezi]. Gaziosmanpaşa Üniversitesi.

Marcus, R.F. (1999). The friendships of delinquents. Adolescence, 31(1), 145-158.

Morsünbül, Ü. (2013). The relationship between identity status and risk taking in adolescence. Elementary Education Online, 12(2), 347-355.

Nikfarjam, P. (2012). Mathematics and play: Analyzing the growth of early elementary mathematical understanding through an enactivist perspective Graduate Program in Education, York University.

Öztürk, H. (2016). Attitudes of students studying in coaching and sport management department towards playing games involving physical activity. Gaziantep University Journal of Social Sciences, 15(2), 717-728.

Patton, M.Q. (2018). Nitel araştırma ve değerlendirme yöntemleri. Pegem Akademi.

Savaş, E., Gülüm, K. (2014). Geleneksel oyunlarla öğretim yöntemi uygulamasının başarı ve kalıcılık üzerine etkisi. Trakya Üniversitesi Sosyal Bilimler Dergisi, 16(1), 183-202.

Tekkurşun Demir, G., Cicioğlu, H.İ. (2018). Fiziksel aktiviteye katılım motivasyonu ölçeği geçerlik ve güvenirlik çalışması. Journal of Human Sciences, 15(4), 2479-2492.

Uğurel, I., Moralı, S. (2008). Matematik ve oyun etkileşimi. Gazi Eğitim Fakültesi Dergisi, 28(3), 75-98.

Uludağlı, N.P., Sayı, 1 M. (2009). Orta ve ileri ergenlik döneminde risk alma davranış1: Ebeveyn ve akranların rolü. Türk Psikoloji Yazılarl, 12(23), 14-24.

Vural, Ö., Eler, S., Güzel, N.A. (2010). Masa başı çalışanlarda fiziksel aktivite düzeyi ve yaşam kalitesi ilişkisi. Spormetre Beden Eğitimi ve Spor Bilimleri Dergisi,8(2), 69-75.

Yıldırım, A., Şimşek, H. (2013). Sosyal bilimlerde nitel araştırma yöntemleri. Seçkin Yayıncılık.

Yıldırım, D.A., Yıldırım, E., Ramazanoğlu, F., Uçar, Ü., Tuzcuoğulları, Ö.T, Demirel, E.T. (2006). Üniversite öğrencilerinin spora bakış açıları ve spor yapma durumu. Doğu Anadolu Bölgesi Araştırmaları Merkezi 4(3), 49-53. 


\section{EXTENDED ABSTRACT}

\section{Investigation of Secondary School Students' Attitudes Towards the Concept of Game and Playing Physical Activity Games in Terms of Some Variables}

When we look at the education systems of developed countries in recent years, it is seen that the concept of play is an important activity for the development of children. According to many scientists, the best way to get to know and observe the child is through play. Children gain many skills while playing. Generally, they learn situations such as learning during the game, making effective decisions, working together, honesty, sharing, respecting the rights of others, loving their friends, helping each other. Through play, the child monitors and perfects his/her skills in transition to adulthood. Play is a useful and effective concept in the development of people at every age stage.

In order to collect the data in the study, the "Attitude Scale Regarding the Concept of Game and Playing Games Containing Physical Activity" was applied to 613 secondary school students studying in schools affiliated to Gaziantep Provincial Directorate of National Education in the 2019-2020 academic year. Before the measurement tool was applied, the purpose of the study was explained to the students who participated voluntarily with the scale. The measurement tool used in the research was applied by the students in approximately 1520 minutes. While filling out the measurement tools, attention was paid to the volunteering of the students.

In this part of the study, which was conducted to examine the attitudes of secondary school students towards the concept of game and playing games containing physical activity, comments and discussions regarding the sub-problems and the findings related to these problems, which were prepared within the framework of the general objectives of the research, were made. In addition, various research results that show similarities or differences with the findings of this research have been examined in the literature and discussions on this subject have been included. In terms of gender variable, in the attitudes of the study group towards playing games containing physical activity; While significant differences were found in favor of men in the sub-dimensions of game passion, risk taking, game desire and enjoyment, it was seen that men had higher scores than women. Therefore, we can state that male students' attitudes towards games involving physical activity are higher. This result may be due to the fact that men's physical activity levels are higher. In terms of class variable, the research group; their attitudes towards playing games that include physical activity; A significant difference was found in the sub-dimensions of game passion, risk taking and social adaptation. According to the results of the Tukey LSD test, which was conducted to determine between which groups the significant difference was; In the sub-dimension of game passion and desire to play, it was observed that the 9th and 10th grade students achieved higher scores than the 12th grade groups. In the risk-taking sub-dimension, it was stated that students in 11th grade achieved higher scores than students in 9th and 10th grades. In the social cohesion sub-dimension, it was observed that the 9th grade students achieved higher scores than the 10th and 11th grade students. In terms of sports history variable, the research group; According to this, it can be said that students with a sports background have more positive attitudes towards games involving physical activity. In terms of the school type variable, a significant difference was found in favor of the Anatolian and science high school students in the social cohesion sub-dimension of the scale in the sub-dimensions of the research group's attitude scores towards playing games containing physical activity. In terms of weight values, 
moderate negative relationships were found between weight and the sub-dimensions of game passion, game desire and enjoyment in the research group's attitude scores towards playing games containing physical activity. Therefore, when the weight increases, it can be said that the passion for the game, the desire for the game and the level of enjoyment decrease.

In terms of height values, no relationship was found between the height values of secondary school students and the scores they obtained from the sub-dimensions of the playfulness scale in the attitude scores of the research group towards playing games containing physical activity. When the opinions of the secondary school students participating in the study on the concept of game are examined; it has been seen that the themes of knowing oneself, the first step of learning, pleasure and happiness, and having fun come to the fore. In addition, regarding the concept of the game, the research group; need, communication tool, preparation for real life, gaining personality, socialization, self-confidence, experience and sharing. From this point of view, we can say that the game contributes in many ways in general. It can be stated that they have an impact especially on getting to know themselves and having fun.

When the opinions of the secondary school students participating in the study on the benefits of the game were examined, most of them stated that the game was beneficial. In addition, regarding the benefits of the game, students; They stated that the learning process is faster and easier, and that it provides the opportunity to learn by doing and experiencing. In addition, secondary school students participating in the research; They expressed the opinion that it is effective in expressing themselves, increases their creativity, and increases their attention and motivation. When the opinions of the secondary school students participating in the study on the adequacy of the playgrounds in their schools are examined, a large proportion of them stated that the playgrounds are not sufficient, while some stated that the playgrounds are enough for luck. 6 students who participated in the study stated that the playgrounds were sufficient.

As a result, men have higher playfulness tendencies than women, younger age and class groups have higher playfulness scores in terms of age and class variables, students with a sports background have more positive attitudes towards games involving physical activity, Anatolian and Science high school students' social cohesion sub-dimension It was concluded that the scores were higher. In addition, when the weight increased, it was determined that the game passion, game desire and enjoyment levels decreased, but no relationship was found with height. In the opinions of the students participating in the study on the concept of game, the themes of knowing oneself, the first step of learning, pleasure and happiness, and having fun came to the fore, and when the views on the benefits of the game were examined, it was concluded that the majority of the game was beneficial, but the playgrounds were not sufficient in the school environment.

"International Journal of New Approaches in Social Studies - IJONASS" is licensed under a Creative Commons Attribution-NonCommercial-ShareAlike 4.0 International License. 